\title{
MONITORIA ACADÊMICA: RELATO DE EXPERIÊNCIA EM DISCIPLINA DE GEOGRAFIA FÍSICA DO INSTITUTO DE CIÊNCIAS HUMANAS - UNIFESSPA
}

\author{
Aubrey-Mar de Souza Rodrigues ${ }^{(a)}$ Maria Rita Vidal ${ }^{(b)}$
}

(a) Faculdade de Geografia- Universidade do Sul e Sudeste do Pará, aubreycarpediem@hotmail.com

(b) Faculdade de Geografia- Universidade do Sul e Sudeste do Pará, ritavidal@unifesspa.edu.br

EIXO: GEOGRAFIA FÍSICA - CURRÍCULO, FORMAÇÃO E PRÁTICAS DE ENSINO

\section{Resumo}

Este trabalho constitui o relato de experiência das atividades de monitoria acadêmica realizadas na disciplina de Geografia Física do curso de Geografia licenciatura e bacharelado da Universidade do Sul e Sudeste do Pará- Unifesspa. Algumas disciplinas ou conteúdos demandam a compreensão sistêmica, com arcabouço teórico metodológico, em que muitas vezes é visto como denso, haja vista que estas disciplinas são lecionadas em períodos iniciais do curso. Assim, o objetivo do trabalho é mostrar como são articulados os conhecimentos geográficos e sistematizadas as atividades para a formação aluno na disciplina. Na formação dos monitores se dão leituras e discussões referentes a disciplina geografia física, bem como organização e seleção de materiais, classificação de sistematização de fotografias, mapas e perfis. Dessa feita, percebeu-se que o exercício da monitoria permite ao licenciando o desenvolvimento de competências e habilidades que lhes serão cobradas quando este partir para o mercado de trabalho.

Palavras chave: monitoria; geografia física; docência; disciplina.

\section{Introdução}

O exercício da monitoria é dar assistência as aulas e aos alunos do curso de Geografia Física, no entendimento dos conteúdos que são ministrados em aulas teóricas e práticas. Ações como, planejar, organizar, sistematizar e acompanhar a execução das aulas práticas teóricas estão presentes no cotidiano do monitor, que através destes tem a possibilidade de aprofundar os conhecimentos na área em questão, ficando dessa forma, visível que as tarefas dos monitores não se restringem apenas a aula. Os programas de monitoria são atividades complementares que oportunizam os estudantes a vivência diferenciada das questões educacionais, além de proporcionar ao aluno (monitor), o desenvolvimento de habilidades inerentes à docência. Dessa feita, aprofundamentos de conhecimentos na área específica contribui com o processo de ensino-aprendizagem dos alunos-monitorados (ASSIS et al., 2006; CARDOSO; DE ARAÚJO, 2008). A monitoria se expressa por ser uma das possibilidades de o monitor efetuar atividades complementares, esta, foi oficialmente instituída no Brasil através da Lei n. ${ }^{\circ}$ 5.540/68 (ASSIS et al., 2006; BORSATTO et al., 2006) e ratificada no art. 84 da Lei n. ${ }^{\circ}$ 9.394, de 20 de dezembro de 1996 na chamada de LDB (BRASIL, 1996), constituindo-se pelo aproveitamento de estudantes nas atividades de ensino, 
pesquisa e extensão. Decretos seguintes delegam às instituições de ensino superior a normatização da atividade de monitoria (BRASIL, 1981). Os programas de monitoria são alicerçados em parâmetros comuns que delegam direitos e deveres à tríade: professor-orientador, aluno-monitor e à instituição de ensino. Estes pontos aliados às ideias contidas no texto de Cardoso e Araújo (2008), que discorre sobre o programa de monitoria em uma disciplina aplicada.

A disciplina de Geografia física faz parte do curso de geografia, sendo uma das disciplinas base do curso, principalmemte quando se faz refência a modalidade bacharelado. A mesma, expressa de forma concisa as abordagens fundamentais da Geografia Física a partir dos marcos epistemológicos que forjam a complexidade da Ciência Geográfica. As categorias e os conceitos da Geografia Física são trabalhados de forma a contribuir com a prática profissional, além de possibilitar uma visão geral das metodologias contemporâneas da análise integrada na Geografia. Ajuda os alunos a ter um conhecimento das definições e dos conceitos básicos da Geografia Física e suas relações e aplicações na análise integrada; contribuindo na análise integrada da Geografia Física com traços fundamentais do planejamento ambiental e territorial ao nível local e regional. Esses aspectos levam os discentes a compreender e dominar os fundamentos metodológicos da Geografia numa perspectiva dialética de forma a contribuir para os procedimentos de trabalho de campo com uso dos métodos da Geografia Física, pautados na elaboração da informação coletada como forma de fazer proposições ao planejamento e ordenamento ambiental. Sendo a Geografia física uma disciplina capaz de desvendar o espaço geográfico a partir das múltiplas relações sociedade natureza, tendo como foco o domínio das técnicas e utilização das geotecnologias. Sendo possível habilitar os discente á elaborar matrizes de impactos ambientais por diferentes técnicas, além de delimitar, classificar, cartografar as unidade de paisagens da região sul e sudeste do Pará, representando -as em mapas temáticos, modelos ou perfis geoecológicos e maquetes. Assim, o objetivo do presente trabalho pauta-se no relato da experiência das atividades de monitoria junto a disciplina de Geografia Física.

\section{Metodologia}

A disciplina de Geografia Física, tem uma carga horária semestral de 68horas, sendo destas 4 horas semanal. A metodologia que se segue para a formação do monitor, se dá através de leituras e discussão em torno da docência e dos conteúdos concernente a disciplina, bem como o levantamento bibliográfico e a organização e seleção de referências bibliográficas. Ainda se executa a seleção, organização de mapas temáticos (geologia, geomorfologia, pedologia, hidrografia, vegetação, etc,), para que os mesmos possam ser trabalhados em sala de aula. As aulas teóricas são realizadas em sala de aula com o uso de mapas temáticos, imagens de satélites, perfis e fotografias aéreas, parte desses materiais foram confeccionados 
XVII Simpósio Brasileiro

de Geografia Fisica Aplicada

I Congresso Nacional

de Geografia Física
OS DESAFIOS DA GEOGRAFIA FÍSICA NA FRONTEIRA DO CONHECIMENTO

Instituto de Geociências - Unicamp

Campinas - SP

28 de Junho à 02 de Julho de 2017

pelo próprio professor regente de sala. $\mathrm{O}$ monitor tem participação ativa por auxiliar o professor e os discentes nas suas práticas ministradas, e/ou em atividade externa ao campus. Essa se torna uma oportunidade para o monitor rever assuntos/temas e empregar sobre os mesmos outras impressões, agregar valores e intervenções didáticas. Os monitores assumem ações para fortalecer e facilitar a compreensão das aulas teóricas e práticas ministradas aos alunos sob supervisão do professor. Para BORSATTO et al., (2006) o incentivo ao magistério superior é uma função inerente da monitoria. Durante as aulas são utilizados vídeos para fazer uma ponte teórica metodológica com os textos em sala, o método utilizado foi discutido para melhor avaliar á aprendizagem do aluno quanto á disciplina e encontrar suas dificuldades ao decorrer das aulas. Também se faz uso do laboratório de cartografia para executar aulas práticas, além de atividades de campo. As avaliações são desenvolvidas de acordo com as atividades da monitoria tendo o professor coordenador acompanhando e assessorando no processo avaliativo. Ao final de cada módulo um relatório parcial é elaborado pela monitoria envolvida, com acertos e desacertos, para redirecionamento em tempo devido.

\section{Relato e experiência}

Como resultado do processo de monitoria, temos um aumento no interesse dos alunos em serem também monitores, mostrando a eficácia do programa na academia. Esse período nos trouxe possibilidades de aprimorar conhecimentos e o despertar para novas perspectivas, principalmente na área da docência, com trabalhos relacionados a mapas, perfis em sala de aula (figura 1)

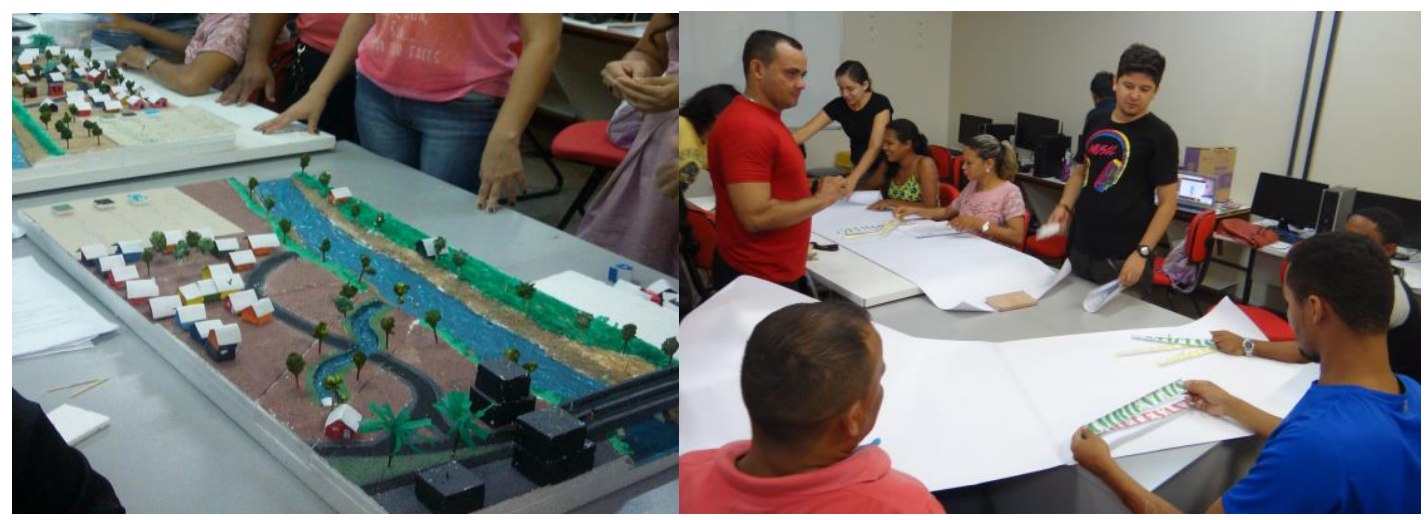

Figura 1- Trabalhos práticos desenvolvidos com as trumas no Laboratório de Geografia Física

A experiência ao lado da professora da disciplina se mostrou como enriquecedora e gratificante, pois agregou novos conhecimentos a minha formação e ao meu currículo. $O$ trabalho de monitoria exige responsabilidade e compromisso, já que este contribui para o processo de 


\section{OS DESAFIOS DA GEOGRAFIA FÍSICA NA FRONTEIRA DO CONHECIMENTO \\ Instituto de Geociências - Unicamp \\ Campinas - SP \\ 28 de Junho à 02 de Julho de 2017}

formação e aprendizagem de muitos alunos. Esta experiência facilita aprender valores muito importantes como comprometimento, ética e profissionalismo, que serão de extrema importância, e que talvez nenhuma outra atividade acadêmica proporcionaria de tal forma. Outro aspecto importante a destacar se pauta nos novos olhares sobre a geografia física, e que até pouco tempo se mostrava distante e complicado.

\section{Conclusão}

$\mathrm{Na}$ monitoria acadêmica todo o processo envolvido mostrou-se um instrumento motivador e eficaz no processo ensino-aprendizagem tanto para os discentes como para o monitor, pois desperta o interesse pela pesquisa e docência. Ampliando e incrementando de forma significativa a formação acadêmica. Dessa feita, espera-se que o monitor se capacite para a sua prática docente, bem como seja facilitada o processo de ensino-aprendizagem junto aos alunos. De forma geral, espera-se que todos os atores envolvidos (professor, alunos e monitor), possam se (des) envolver na melhoria da qualidade do ensino-aprendizagem e no processo de formação do professor em Geografia.

\section{REFERÊNCIAS}

ASSIS, F.D. et al. Programa de Monitoria Acadêmica: percepções de monitores e orientadores. . UERJ, v.14, n.3, p.391-397, jul.-set. 2006

BORSATTO, A.Z. et al. Processo de implantação e consolidação da monitoria acadêmica na UERJ , jul.set. 2006.

CARDOSO, M.C. e DE ARAÚJO, R.P. Monitoria acadêmica: relato de experiência em disciplina aplicada da Terapia Ocupacional. Cadernos de Terapia Ocupacional da UFSCar, v.16, n.1, p.53-57, janjun. 2008.

BRASIL. Decreto ${ }^{\circ} 85.862$, de 31 de março de 1981. Atribui competência às instituições de ensino superior para fixar as condições necessárias ao exercício das funções de monitoria, e dá outras providências. Diário Oficial da União, Brasília

ROSS, Jurandi Luciano Sanches. Ecogeografia do Brasil: subsídios para planejamento ambiental. São Paulo: Oficina de textos, 2006. 


\begin{tabular}{|c|c|}
\hline $\begin{array}{l}\text { XVII Simpósio Brasileiro } \\
\text { de Geografia Fisica Aplicada }\end{array}$ & $\begin{array}{l}\text { OS DESAFIOS DA GEOGRAFIA FÍSICA NA FRONTEIRA DO CONHECIMENTO } \\
\text { Instituto de Geociências - Unicamp }\end{array}$ \\
\hline $\begin{array}{l}\text { I Congresso Nacional } \\
\text { de Geografia Física }\end{array}$ & $\begin{array}{c}\text { Campinas - SP } \\
28 \text { de Junho à } 02 \text { de Julho de } 2017\end{array}$ \\
\hline
\end{tabular}

